\title{
REBEn Trajetória e tendências dos Cursos de Enfermagem no Brasil
}

\author{
Trajectory and trends of Brazilian Nursing Diploma Courses \\ Trayectoria y tendencias de los Cursos de Graduación en Enfermería en Brasil
}

\section{Elizabeth Teixeira}

Doutora. Professora do Curso de Enfermagem da Universidade do Estado do Pará, Belém, PA.

Eucléia Gomes Vale

Doutoranda em Enfermagem na UFC. Professora da Faculdade Católica Rainha do Sertão, Fortaleza, CE.

\section{Josicelia Dumêt Fernandes}

Doutora. Professora Titular da Escola de Enfermagem da Universidade Federal da Bahia, Salvador, BA.

\section{Mara Regina Lemes De Sordi}

Doutora. Professora da Faculdade de Enfermagem da Pontifícia Universidade Católica de Campinas, Campinas, $S P$.
Submissão: 10/05/2006

Aprovação: 30/06/2006

\section{RESUMO}

O texto analisa a trajetória da educação em enfermagem no Brasil; analisa as tendências dos cursos de graduação (1991-2004) e traça um perfil do estudante de graduação de enfermagem que participou do Exame Nacional de Cursos (ENADE), em 2004. Para traçar o referido perfil são utilizados 18 indicadores sócio-familiares e acadêmicos dos respondentes do questionário do aluno. Apontam-se algumas perspectivas e desafios à educação em enfermagem no país, com vistas a subsidiar educadores e educandos na sua prática acadêmica. Descritores: Enfermagem; Educação em enfermagem; Programas de graduação em enfermagem.

\section{ABSTRACT}

The text analyzes the path of the education in nursing in Brazil and analyzes the trends of the diploma courses (1991-2004) and describes a profile of the nursing graduation students that participated in the National Exam of Courses (ENADE), in 2004. To draw the referred profile 18 partner-family indicators and the respondents of the student's questionnaire academics they used. Some perspectives and challenges are pointed to the education in nursing in the country, with views to subsidize educators and students in his/her academic practice. Descriptors: Nursing; Nursing, education; Education, nursing, diploma programs.

\section{RESUMEN}

El texto analiza el camino de la educación de enfermeria en Brasil y las tendencias de los cursos del grado (1991-2004) y polilla un perfil del estudiante graduación en enfermeria han participado en el Examen Nacional de Cursos (ENADE), en 2004. Para dibujar el referido 18 indicadores del compañero-familia y los respondentes al perfil de los académicos de la encuesta del estudiante ellos se usan. Se apuntan un poco de perspectivas y desafíos a la educación em enfermería en el país, con las vistas para subvencionar a educadores y estudiantes en el his/her la práctica académica.

Descriptores: Enfermería; Educación en enfermería; Programas de graduación en enfermería.

Teixeira E, Vale EG, Fernandes JD, De Sordi MRL. Trajetória e tendências dos Cursos de Enfermagem no Brasil. Rev Bras Enferm 2006 jul-ago; 59(4): 479-87.

\section{INTRODUÇÃO}

Conhecer a realidade da educação em enfermagem, sua trajetória, tendências e as contradições que a perpassam é decisivo. Mas exige apropriação qualificada, matizada pela reflexão das conseqüências éticas destas tendências.

Nesse entendimento, foram tomadas como base referencial, as Diretrizes Curriculares Nacionais do Curso de Graduação em Enfermagem, documentos emanados do Instituto Nacional de Pesquisas (INEP/MEC), Censo da Educação Superior e ENADE.

Os dados do Enade se constituem em um dos indicadores de qualidade dos cursos de graduação. Os dados do Censo Escolar possibilitam compreender a situação dos cursos no país, com seus desequilíbrios regionais, permitindo levar em conta estes cenários na interpretação dos resultados dos exames. Os dados do questionário do Enade, respondido pelos ingressantes e concluintes dos cursos, tentam capturar seu perfil sócio-cultural-econômico para favorecer um tratamento adequado dos cursos a estas variáveis.

Os indicadores adotados para fins de análise foram: cursos, candidatos, vagas, ingressantes e concluintes, segundo regiões e categorias administrativas das IES fornecidos pelo Censo da Educação Superior e Relatório do ENADE 2004, tendo como abrangência, o período de 1991 a 2004. 


\section{TRAJETÓRIA DA EDUCAÇÃO EM ENFERMAGEM NO BRASIL}

A primeira tentativa de sistematização do ensino de enfermagem no Brasil ocorreu em 1890, quando da criação, na cidade do Rio de Janeiro, da Escola Profissional de Enfermeiros, no Hospício Nacional de Alienados, com a finalidade de preparar enfermeiros para os hospícios e hospitais civis e militares ${ }^{(1,2)}$.

Essa tentativa emergiu de um processo político que, ultrapassando as fronteiras do Hospício Nacional de Alienados, pôs em confronto 0 poder da Igreja, o poder do Estado e a classe médica ${ }^{(2,3)}$.

Por volta de 1901, foi criado, sob a orientação de enfermeiras inglesas, um outro curso, no então Hospital Evangélico (hoje Hospital Samaritano), em São Paulo. Esse curso foi criado com o objetivo de preparar pessoal para o referido hospital que se destinava ao atendimento de estrangeiros residentes no Brasil.

Com as repercussões da Primeira Guerra Mundial, a Cruz Vermelha Brasileira deu início, por volta de 1916, na cidade do Rio de Janeiro, a um curso de enfermagem (Escola Prática de Enfermeiras da Cruz Vermelha), com a finalidade de preparar voluntários para as emergências de guerra ${ }^{(2,3)}$.

Esses cursos foram criados para atender às necessidades emergenciais de cada momento histórico, sem, contudo, atenderem aos padrões da enfermagem moderna, semelhantes aos que, em 1860, já havia sido estabelecido em Londres, por Florence Nightingale.

Durante o predomínio do modelo econômico agrário-exportador, não havia, por parte do Estado, uma política explícita que indicasse uma preocupação com a saúde da população e, conseqüentemente, com uma mão de obra de enfermagem qualificada ${ }^{(2,3)}$.

A problemática da Saúde Pública, configurada na crise econômica da década de 20, demandou novas e amplas respostas do Estado que criou o Departamento Nacional de Saúde Pública e, posteriormente, em 1923, a Escola de Enfermeiras desse mesmo Departamento. Essa escola, que mais tarde passou a chamar-se Escola de Enfermeiras D. Ana Néri, foi criada dentro dos moldes nightingalianos, daí ser considerada a primeira escola de enfermagem moderna do país.

A emergência do ensino de enfermagem moderna em nosso país coincide, pois, com o momento em que surgem os primeiros traços de uma política de saúde por parte do Estado, ou seja, com o momento em que a questão da saúde ganha uma nova dimensão, passando a ser uma das atribuições do Estado(2,3).

O processo de reorganização econômico-política, a partir da década de 30 , evidencia a necessidade de uma força de trabalho qualificada e com saúde. No bojo desse processo, começou a evolução dos cursos de enfermagem moderna no país. Essa evolução, contudo, só é acionada na década de $40 \mathrm{com}$ a aceleração do processo de substituição das importações e fortalecimento do processo de industrialização.

Nesse contexto, e atendendo a lógica de produção de serviços de saúde, o Estado, através da Lei $n^{0} 775$ de 06/08/1949, propõe a ampliação do número de escolas, tornando obrigatória a existência do ensino de enfermagem em todo centro universitário ou sede de faculdades de medicina, além de definir um ensino voltado para a área hospitalar, centrado no modelo clínico e com aderência ao mercado de trabalho à época ${ }^{(4)}$.

O ensino de enfermagem, destarte, apesar de ter sido institucionalizado em 1923, sob a influência do sanitarismo, só a partir do desenvolvimento industrial e modernização dos hospitais é que passa a ser consolidado. A institucionalização do ensino de enfermagem no Brasil, portanto, está contida num contexto que ganha suas amplas dimensões quando remetida aos problemas de organização e funcionamento da sociedade e do Estado.

Em 1968, através da Reforma Universitária, apregoa-se a ampliação do número de vagas e a modernização do ensino superior, além da conseqüente necessidade de revisão dos currículos mínimos dos cursos.

Como integrante do aparelho universitário, o ensino de enfermagem seguiu as determinações da Reforma Universitária, que, em síntese, estavam dirigidas para a formação de maior número de profissionais e na reestruturação de um novo currículo mínimo, formalizado pelo Parecer n' 163/72 e Resolução 4/72 do, então, Conselho Federal de Educação. Um currículo voltado para o modelo biologicista, individualista e hospitalocêntrico, marcado por uma visão tecnicista da saúde, dificultando a compreensão dos determinantes sociais do processo saúde/doença.

Com o processo de redemocratização do país, a partir da década de 80, dois marcos merecem ser destacados: a VIII Conferência Nacional de Saúde e a promulgação da Constituição em 1988, pois se constituíram expressão de um processo de luta de diferentes atores da sociedade por ampliação de direitos sociais.

AAssociação Brasileira de Enfermagem (ABEn), como um dos atores engajados nesse processo de luta, desencadeia um amplo debate por meio dos Seminários Nacionais e Regionais sobre "Perfil e Competência de Enfermeiros" e "Proposta de Currículos Mínimos de Enfermagem", mobilizando docentes, discentes e profissionais dos serviços, objetivando a construção coletiva de um projeto educacional para a enfermagem brasileira. A troca de experiências e a riqueza das discussões geradas nesse movimento subsidiaram o Parecer 314/94 do, então, Conselho Federal de Educação, homologado pela Portaria 1.721 do Ministério da Educação, em 15/12/1994.

Ademais, a $A B E n$, mantendo-se vigilante ao desenvolvimento do ensino de enfermagem no país, cria, a partir de 1994, os Seminários Nacionais de Diretrizes para a Educação em Enfermagem (SENADEns) que trouxeram contribuições significativas para a construção das Diretrizes Curriculares Nacionais do Curso de Graduação em Enfermagem, além de se constituírem em espaços para aprofundamento da construção coletiva das políticas e propostas que dizem respeito à educação em enfermagem.

Em 1996 é aprovada a Lei de Diretrizes e Bases da Educação Nacional (LDB), Lei 9.394 de 20/12/1996 (5), que estabelece as diretrizes e bases da educação nacional, abrindo espaços para a flexibilização dos currículos de graduação, para a expansão de cursos e vagas na educação superior, além de direcionar a construção de Diretrizes Curriculares para cada Curso de Graduação.

A partir da LDB, concretizou-se, em 7/8/2001, o Parecer 1133 do CNE/CES ${ }^{(6)}$, que veio reforçar a necessidade da articulação entre Educação Superior e Saúde, objetivando a formação geral e específica dos egressos/profissionais, com ênfase na promoção, prevenção, recuperação e reabilitação da saúde. Após esse Parecer, foi aprovada a Resolução CNE/CES No 03 de 7/11/2001(7), que definiu as Diretrizes Curriculares Nacionais para o Curso de Graduação em Enfermagem (DCENF).

As DCENF tiveram sua materialidade concretizada, a partir de propostas que emergiram da mobilização das (os) enfermeiras (os), por meio da sua associação de classe, de entidades educacionais e de setores da sociedade civil interessados em defender as mudanças da formação na área da saúde. Elas expressam os conceitos originários dos movimentos por mudanças na educação em enfermagem, explicitando a necessidade do compromisso com princípios da Reforma Sanitária Brasileira e do Sistema Único de Saúde (SUS). Elas devem ser apreendidas, destarte, como produto de uma construção social e histórica, trazendo, no seu conteúdo, os posicionamentos da enfermagem brasileira como ponto de partida para as mudanças necessárias à formação da (0) enfermeira (0) e como referência para que as escolas/cursos, no uso de sua autonomia, construam, coletivamente, seus Projetos Pedagógicos, respeitando a especificidade regional, local e institucional. 
A implantação/implementação das DCENF implica um grande desafio que é o de formar enfermeiras (os) com competência técnica e política, como sujeitos sociais dotados de conhecimento, de raciocínio, de percepção e sensibilidade para as questões da vida e da sociedade, capacitando-as (os) para intervirem em contextos de incertezas e complexidade( ${ }^{(8)}$.

\section{TENDÊNCIAS DOS CURSOS DE GRADUAÇÃO EM ENFERMAGEM NO BRASIL}

Até 1947 foram criados, no Brasil, 16 cursos de enfermagem. No período de 1947 a 1964 foram criados mais 23 cursos, ou seja, um crescimento de $43,75 \%$ em 17 anos.

Esse crescimento foi mais acentuado a partir do final da década de 1960, quando se dá a expansão do ensino de enfermagem no país ${ }^{(3)}$. Assim é que se em 1964 existiam 39 cursos, em 1991 passaram a existir 106 cursos, ou seja, uma expansão de 171\%.

De acordo com os dados disponibilizados pelo MEC/INEP/DEAS, em 1991 existiam 106 cursos de graduação em enfermagem. Em 2004 esse número passou para 415, o que significa um incremento de $291,5 \%$. Essa expansão foi mais forte a partir da LDB, pois de 1991 até 1996 foram criados apenas 5 cursos, ou seja, um incremento de $4,71 \%$, enquanto que de 1996 a 2004, foram criados 304 cursos, indicando uma expansão de $286,79 \%$.

Essa expansão, contudo, não se deu de maneira uniforme. Ela se deu, predominantemente, na região sudeste, passando de 50 cursos em 1991 para 220 , em 2004, ou seja, um crescimento de $340 \%$, seguida da região sul que passou de 21 cursos, em 1991, para 84, em 2004, o que significa uma expansão de $300 \%$. Devido ao aumento do número de cursos na região centro-oeste, de 5, em 1991, para 29, em 2004, essa região apresentou maior participação proporcional de crescimento de cursos.

Essas desigualdades regionais refletem o desenvolvimento industrial das regiões sudeste e sul, que, por sua vez, favorecem uma demanda por serviços qualificados.

Vale destacar, ainda, que a desigualdade na oferta de cursos se faz presente não apenas entre as regiões, mas também no interior das mesmas, ou seja, dos 220 cursos existentes na região sudeste, 109 $(49,54 \%)$ estão no estado de São Paulo. Por outro lado, observa-se uma enorme concentração de investimentos públicos onde a capacidade instalada de recursos humanos qualificados e de infra-estrutura préexistentes já é consideravelmente elevada. Onde existe o maior PIB ou maior número de cursos, o valor dos investimentos absolutos tem sido proporcionalmente maior ${ }^{(9)}$.

Tabela 1. Oferta dos Cursos de Graduação em Enfermagem por região geográfica (1991-2004).

\begin{tabular}{l|ccc}
\hline \multicolumn{1}{c|}{ REGIÕES } & TOTAL EM 1991 & TOTAL EM 2004 & Dif \% \\
\hline Centro-Oeste & 5 & 29 & 480,0 \\
Sudeste & 50 & 220 & 340,0 \\
Sul & 21 & 84 & 300,0 \\
Nordeste & 22 & 61 & 177,3 \\
Norte & 8 & 21 & 162,5 \\
\hline TOTAL & 106 & $\mathbf{4 1 5}$ & $\mathbf{2 9 1 , 5}$ \\
\hline
\end{tabular}

Fonte: MEC/INEP/DEAS.

A figura 1 revela que o aumento de cursos em todas as regiões do país melhorou a relação oferta de cursos por 1.000 .000 habitantes, com destaque para as regiões centro-oeste, sul e sudeste. Esse dado reclama por uma análise qualitativa que leve em conta alguns fatores como: necessidades de saúde da população, relação enfermeiro por habitante, quantitativo atingido e atendimento das necessidades de sustentação do modelo de atenção à saúde vigente no país, respeitando os parâmetros de dimensionamento de pessoal de enfermagem e as prerrogativas da lei do exercício profissional, produzindo impacto nos indicadores de saúde. Destaca-se que não basta ampliar os números de cursos/vagas sem o simultâneo investimento na expansão e adequação dos serviços, com vistas a inserção do profissional nesse mercado de trabalho. 0 crescimento do número de cursos/vagas merece um efetivo sistema de regulação por parte do Estado, no que se refere as condições de ensino, ou seja, a infra-estrutura, a política de recursos humanos e a organização didático-pedagógica., tanto na rede pública como na privada.

Além da desigualdade regional na oferta de cursos, observa-se,

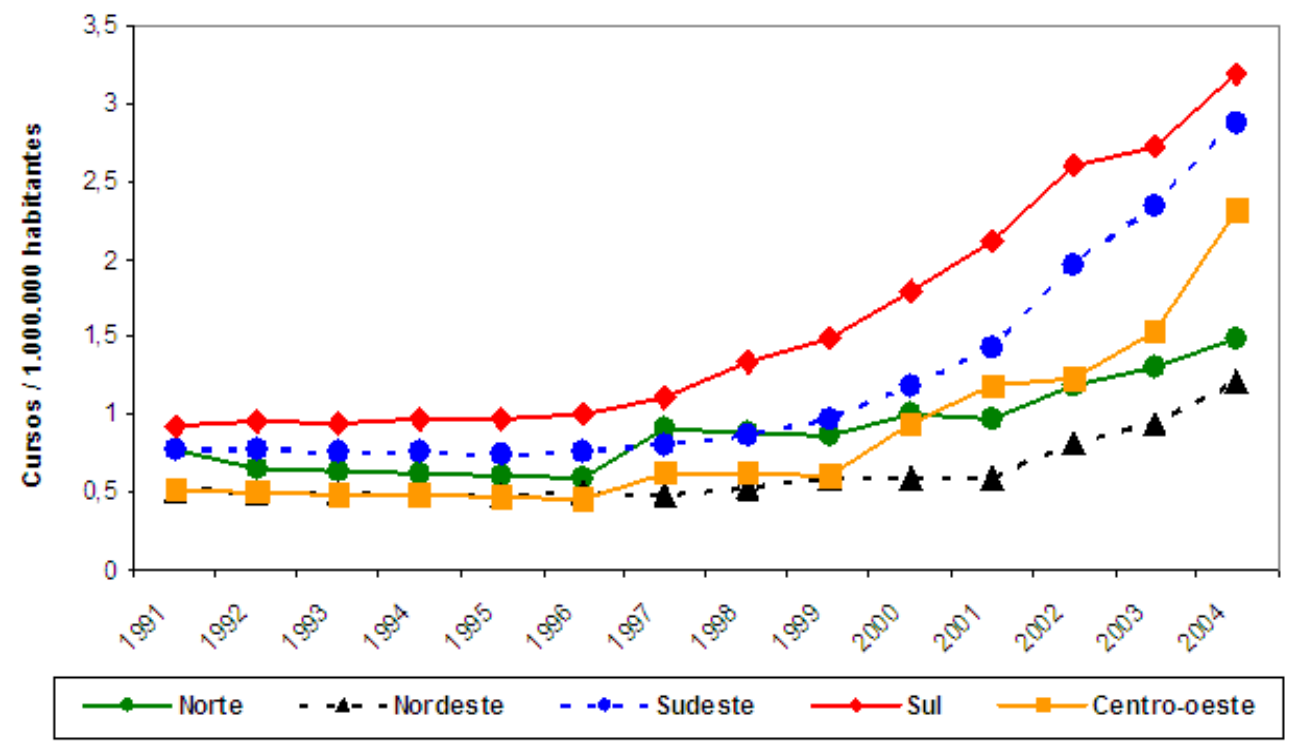

Figura 1. Número de Cursos de Graduação em Enfermagem por 1.000 .000 habitantes por região geográfica (1991-2004). 


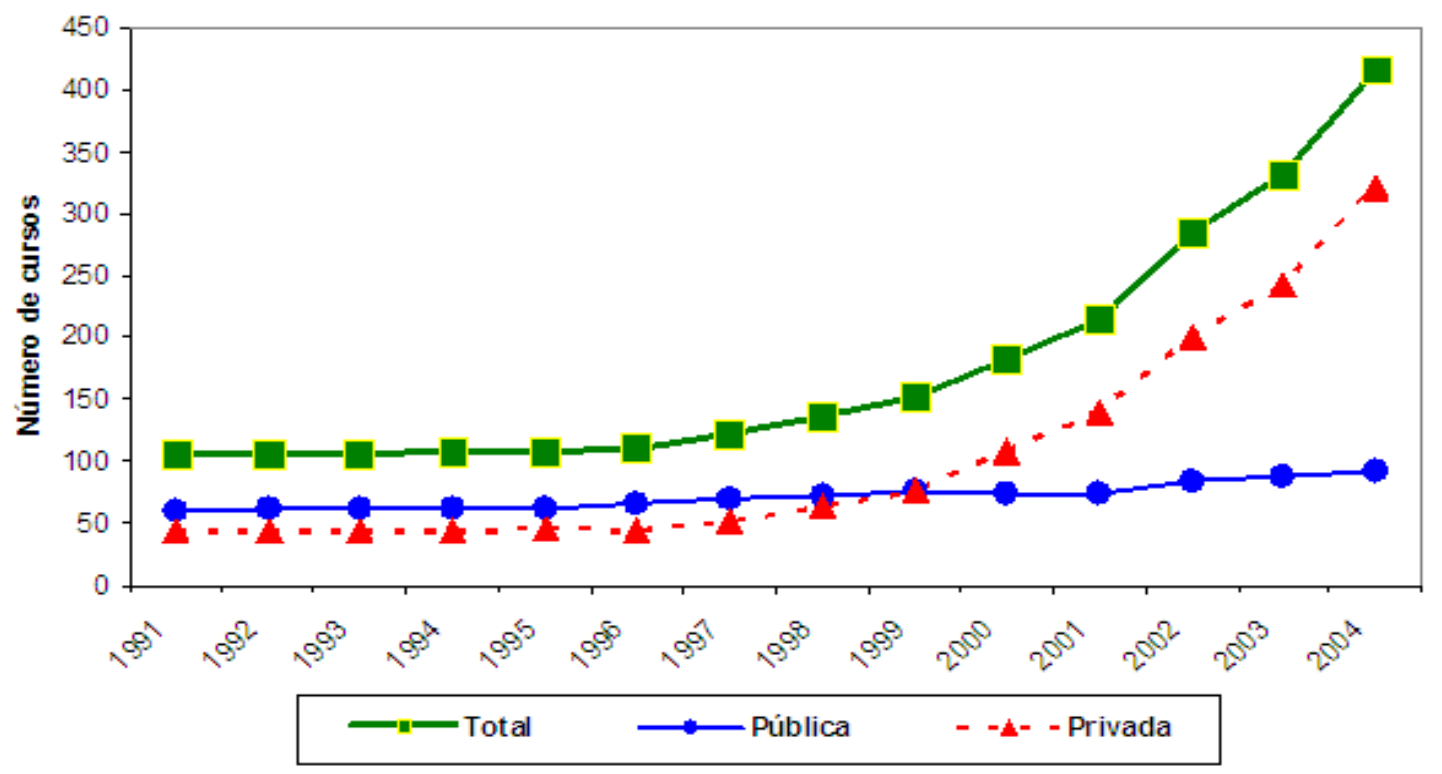

Figura 2. Oferta de cursos de graduação em enfermagem por categoria administrativa (1991-2004).

também, um desequilíbrio na distribuição dos cursos por categoria administrativa. Conforme ilustrado no Figura 2, o crescimento dos cursos da rede pública foi menor do que os da rede privada. Os cursos da rede pública passaram de $61 \mathrm{em}$ 1991, para 93 em 2004, representando um incremento na ordem de $52,45 \%$, enquanto que nos cursos da rede privada esse incremento foi de $615,55 \%$, ou seja, passaram de 45 para 322.

Esse desequilíbrio entre os cursos da rede pública e rede privada expressa a premissa mercadológica da educação superior que valorizou o mercado econômico como elemento fundamental na criação de novos cursos e instituições.

Vale salientar que esse crescimento da rede privada tornou-se mais acentuado, a partir de 1997. Se em 1996 existiam 45 cursos da rede privada, em 2004 esse número passou para 322, ou seja, um incremento de $837,77 \%$. Esse incremento encontra respaldo na autonomia dada às instituições de ensino superior e na flexibilização dos currículos em decorrência da LDB, a partir de 1996.

A oferta de vagas oferecidas nos cursos manteve a mesma dinâmica da distribuição de cursos. Em 1991 existiam 7.460 vagas, passando

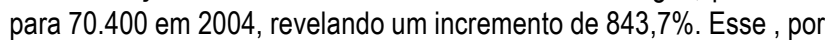
sua vez, se deu principalmente, a partir da aprovação da LDB, ou seja, se no período de 1991 a 1996, o aumento foi de $11,03 \%$, no período de 1996 a 2004 o incremento foi de $749,93 \%$.

Mais uma vez, a região responsável por essa ampliação foi a região sudeste que passou de 3.785 vagas, em 1991, para 47.301 em 2004 , revelando uma expansão de 1.149,7\%, conforme ilustrado na Tabela 2.

Tabela 2. Vagas de Cursos de Graduação de Enfermagem por região geográfica (1991-2004).

\begin{tabular}{c|ccc}
\hline REGIÕES & VAGAS 1991 & VAGAS 2004 & Dif \% \\
\hline Centro-Oeste & 294 & 4.709 & 1501,7 \\
Sudeste & 3.785 & 47.301 & 1149,7 \\
Sul & 1.450 & 8.146 & 461,8 \\
Nordeste & 1.501 & 7.824 & 421,3 \\
Norte & 430 & 2.420 & 462,8 \\
\hline TOTAL & $\mathbf{7 . 4 6 0}$ & $\mathbf{7 0 . 4 0 0}$ & $\mathbf{8 4 3 , 7}$ \\
\hline
\end{tabular}

Fonte: MEC/INEP/DEAS.
O maior crescimento da oferta de vagas na região sudeste se deu no Estado São Paulo que passou de 2.120 vagas em 1991 para 26.907 em 2004, revelando a desigualdade inter e intra-regional.

Seguindo essa mesma dinâmica, observa-se no Figura 3 que a oferta de vagas por categoria administrativa passou de 3.835, em 1991 para 5.597 , em 2004, na rede pública, tendo um incremento de $45,99 \%$. Na rede privada, esse crescimento foi de 3.625, em 1991 para 64.803, em 2004 , o que revela um incremento de $1.687,66 \%$.

A Tabela 3 evidencia a mesma dinâmica dos desequilíbrios regionais, apontando a região sudeste como a de maior número de candidatos a cursos de graduação em enfermagem, no período estudado.

Tabela 3. Candidatos para cursos de graduação em enfermagem por região geográfica (1991-2004).

\begin{tabular}{lccc}
\hline \multicolumn{1}{c}{ REGIÕES } & CANDIDATOS 1991 & CANDIDATOS 2004 & Dif \% \\
\hline Centro-Oeste & 1.497 & 17.004 & 1035,9 \\
Sudeste & 11.139 & 113.459 & 918,6 \\
Sul & 3.946 & 22.707 & 475,4 \\
Nordeste & 9.342 & 57.913 & 519,9 \\
Norte & 3.071 & 19.597 & 538,1 \\
\hline TOTAL & $\mathbf{2 8 . 9 9 5}$ & $\mathbf{2 3 0 . 6 8 0}$ & $\mathbf{6 9 5 , 6}$ \\
\hline
\end{tabular}

O número de candidatos para cursos de graduação, também, além de ter tido maior crescimento na região sudeste, essa expansão foi maior na rede privada, que apresentou um incremento de 1.342,47\%, conforme ilustrado no Figura 4.

Por meio dos Figuras 5 e 6 , pode-se observar que, se por um lado 0 acesso aos cursos de enfermagem apresentou importante crescimento, em termos dos ingressantes, concentrado nitidamente na iniciativa privada $(684,9 \%)$, o número de concluintes, no período estudado revela uma queda nos indicadores. Cabe interrogar as razões de tal fenômeno e seu significado para a definição de políticas públicas, visto que a perda numérica é expressiva, também, na rede pública. Se no sistema privado poderia ser atribuída alguma responsabilidade à variável socioeconômica, o que o dado poderia representar nas escolas públicas? 


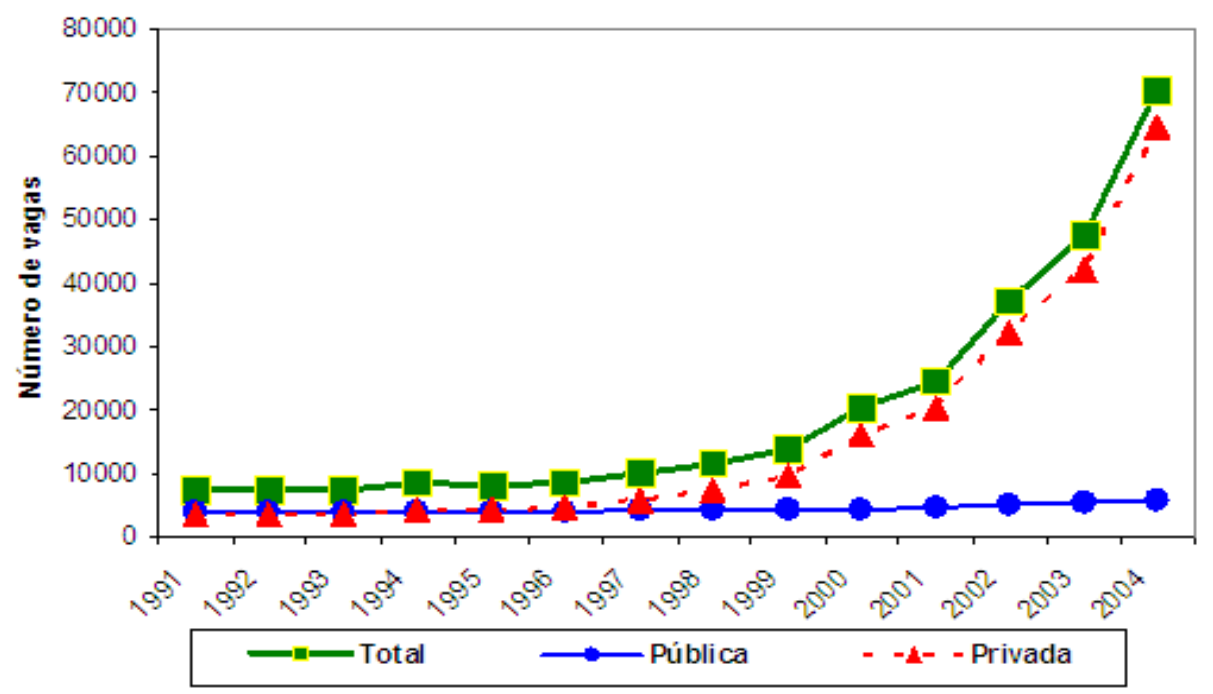

Figura 3. Número de vagas nos Cursos de Graduação em Enfermagem por categoria administrativa (1991-2004).

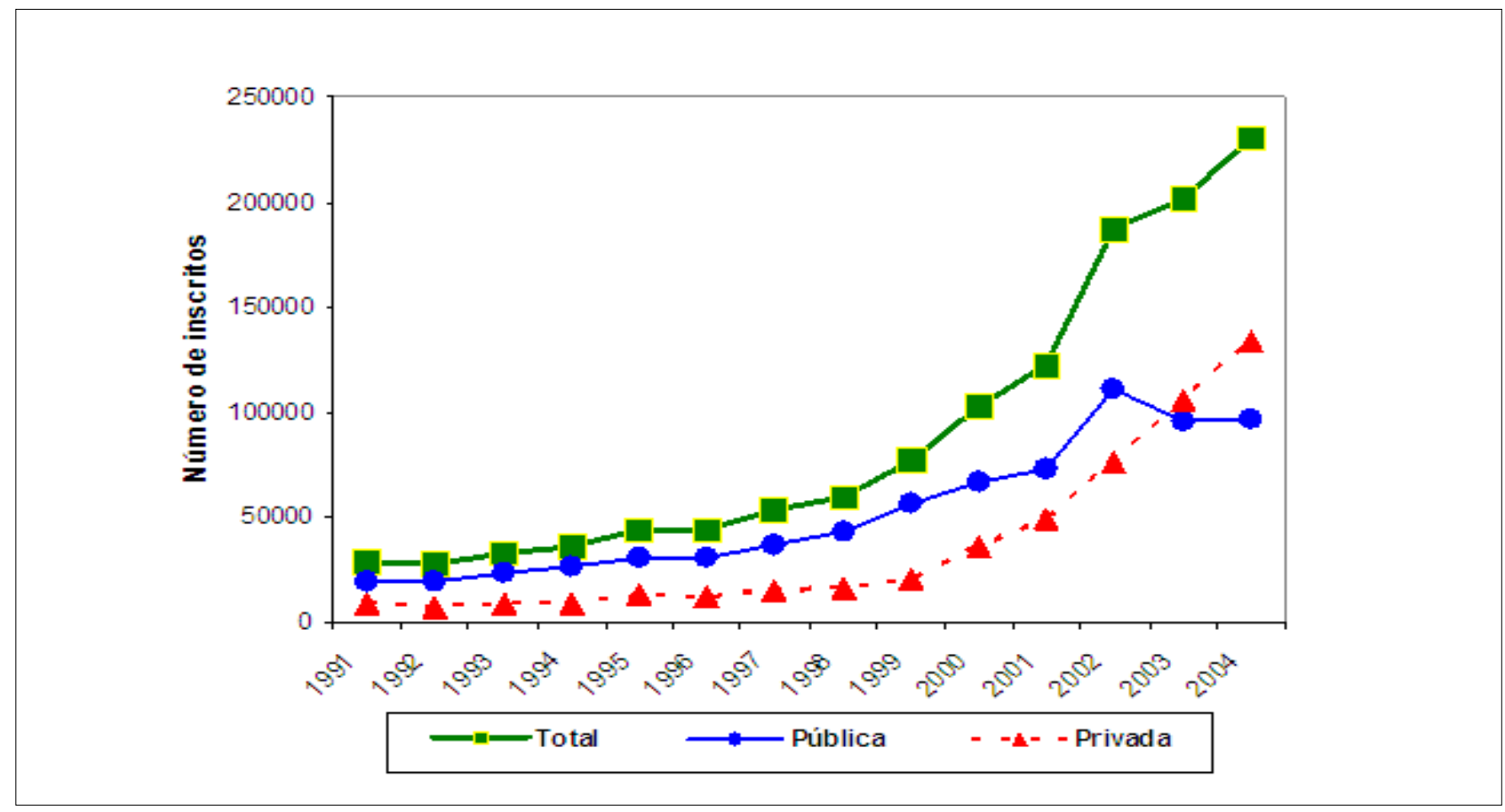

Figura 4. Inscritos para o processo seletivo nos Cursos de Graduação em Enfermagem por categoria administrativa (1991-2004).

$O$ que se pode afirmar é que essa realidade indica que a capacidade instalada está sub-aproveitada, podendo repercutir negativamente no plano social, ou seja, o número de vagas oferecido não é plenamente utilizado. Esse resultado nos faz pensar que o investimento no âmbito da graduação em enfermagem pode não estar repercutindo, necessariamente, em retorno proporcional às necessidades de saúde da população.

Por meio dos Figuras 5 e 6 , pode-se observar que, se por um lado 0 acesso aos cursos de enfermagem apresentou importante crescimento, em termos dos ingressantes, concentrado nitidamente na iniciativa privada $(684,9 \%)$, o número de concluintes, no período estudado revela uma queda nos indicadores. Cabe interrogar as razões de tal fenômeno e seu significado para a definição de políticas públicas, visto que a perda numérica é expressiva, também, na rede pública. Se no sistema privado poderia ser atribuída alguma responsabilidade à variável socioeconômica, o que o dado poderia representar nas escolas públicas? 0 que se pode afirmar é que essa realidade indica que a capacidade instalada está sub-aproveitada, podendo repercutir negativamente no 


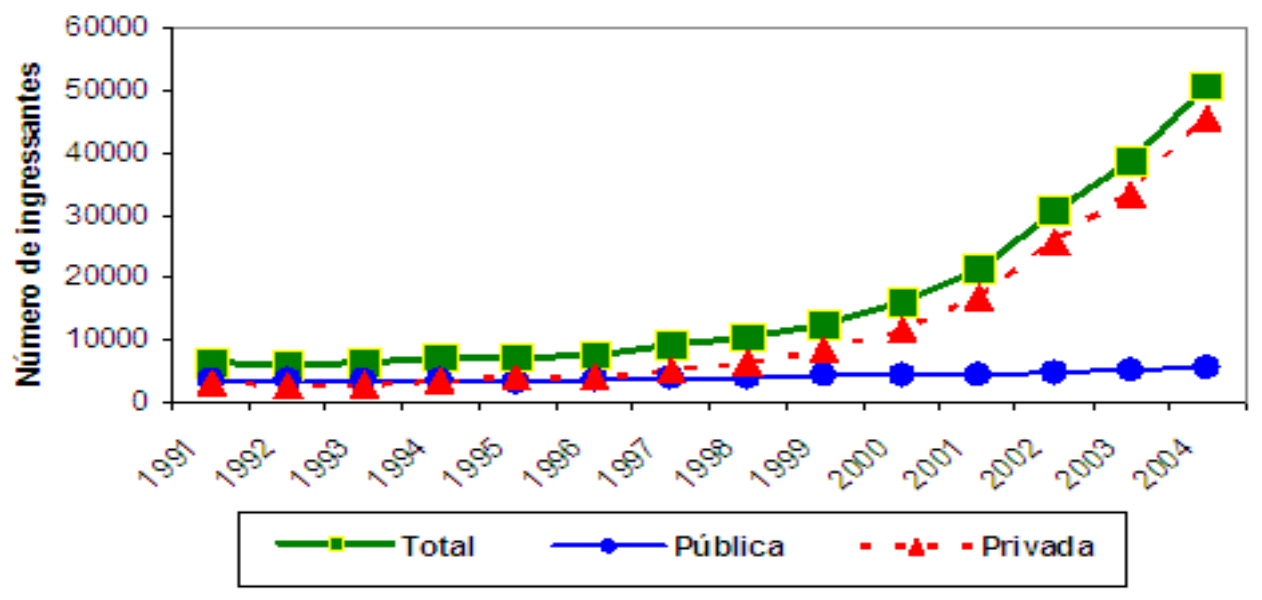

Figura 5. Número de ingressantes nos Cursos de Graduação em Enfermagem por categoria administrativa (1991-2004).

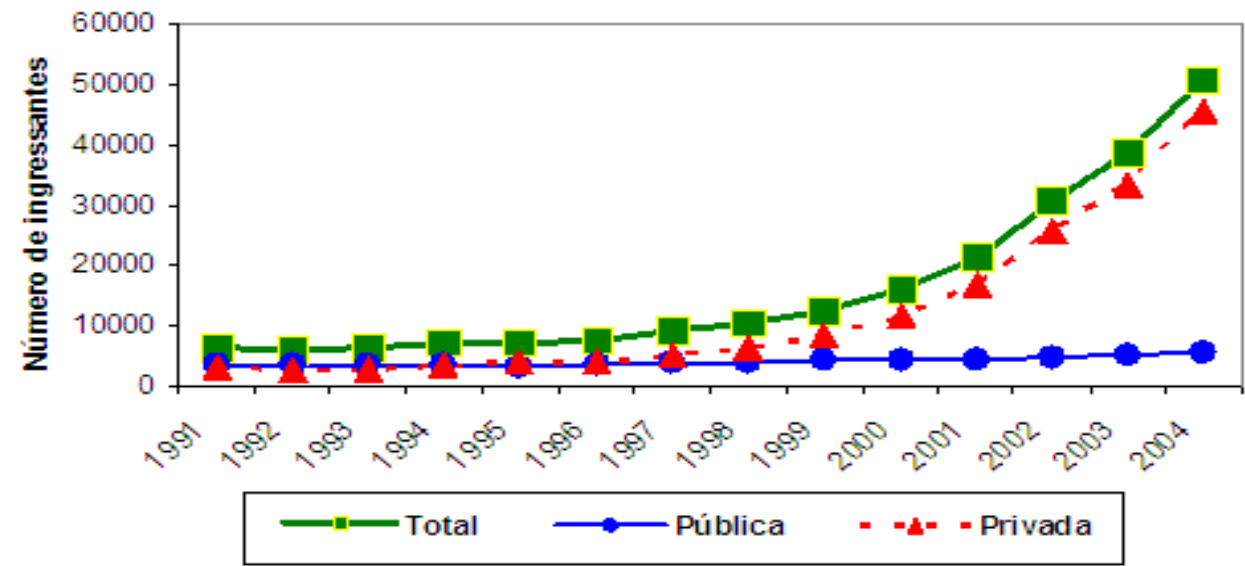

Figura 6. Número de concluintes nos Cursos de Graduação em Enfermagem por categoria administrativa (1991-2004).

plano social, ou seja, o número de vagas oferecido não é plenamente utilizado. Esse resultado nos faz pensar que o investimento no âmbito da graduação em enfermagem pode não estar repercutindo, necessariamente, em retorno proporcional às necessidades de saúde da população.

\section{PERFIL DO ESTUDANTE DE ENFERMAGEM: ENADE-2004}

O Exame Nacional de Desempenho dos Estudantes (ENADE), se insere como um dos instrumentos de avaliação do Sistema Nacional de Avaliação da Educação Superior (SINAES), e tem como objetivos: aferir o desempenho dos estudantes em relação aos conteúdos programáticos previstos nas diretrizes curriculares, suas habilidades para ajustamento às exigências decorrentes da evolução do conhecimento e suas competências para compreender temas exteriores ao âmbito específico de sua profissão.

OENADE-2004 envolveu 352 cursos de enfermagem, dos quais $52,8 \%$ encontravam-se na Região Sudeste, $77,8 \%$ na rede privada, $54,8 \%$ em universidades e $25 \%$ dos cursos, localizados no Estado de SP.

Participaram do exame 46.859 estudantes $(76,1 \%$ ingressantes e $23,9 \%$ concluintes). A distribuição dos mesmos seguiu o mesmo perfil de distribuição dos cursos: $62,7 \%$ da região sudeste, $85,5 \%$ da rede privada, $55,6 \%$ de universidades, $35 \%$ do estado de São Paulo. Todos os estudantes receberam um questionário-pesquisa com 106 questões sobre o perfil sócio-familiar e acadêmico dos estudantes e sobre as condições dos cursos de graduação em que estudam. Deste universo, responderam ao questionário-pesquisa uma amostra de 40,7\% de ingressantes e $57 \%$ de concluintes.

Neste estudo foram escolhidos 18 indicadores do perfil sócio-familiar e acadêmico dos estudantes, que serão apresentados de acordo com as respostas dos ingressantes e concluintes, respectivamente. Considerando os dados apresentados nesses indicadores destacados e os maiores resultados, pode-se descrever o perfil do estudante de enfermagem que respondeu ao questionário-pesquisa do ENADE 2004 (ingressante e concluinte).

As (os) ingressantes são, predominantemente do sexo feminino, com 
até 24 anos de idade, solteiras (os), apresentando-se como de cor branca, com renda entre 3 e 10 salários mínimos, trabalhadoras (es), sem nenhum financiamento para custeio das despesas, pais com escolaridade da $1^{\mathrm{a}}$ a $4^{\mathrm{a}}$ série, mães com ensino médio, cursaram ensino médio todo em escola pública, conhecimentos praticamente nulos da língua inglesa, usam a TV para se atualizar, freqüentam razoavelmente a biblioteca da IES, estudam de 1 a 2 horas por semana, não desenvolvem atividades além das obrigatórias, usam, às vezes, microcomputador, acessam a internet e usam microcomputador em casa.

0 perfil das (os) estudantes de enfermagem concluintes pouco se diferencia das (os) ingressantes. $E$ isso merece ser problematizado especialmente em um estudo de tendências da educação. Os dados das (os) concluintes sinalizam que estes, de modo ainda marcante (51\%), têm dupla jornada e uma importante porcentagem (31\%) não desenvolve nenhuma atividade além das obrigatórias previstas na dinâmica curricular. Vejamos a seguir as categorias que compõem o perfil das (os) estudantes.

No que se refere à questão do gênero, o perfil das (os) estudantes do ENADE 2004 reforça duas tendências já constatadas na literatura. A primeira diz respeito à relação historicamente construída entre a mulher e o cuidar. A segunda refere-se à relação socialmente construída entre a mulher e a opção pelos cursos de enfermagem.

A permanente predominância do sexo feminino na profissão, além de indicar a presença da mulher no mercado de trabalho, sinaliza a possibilidade de acesso ao ensino superior em profissões consideradas como de menor status social. Cabe ressaltar que essa crescente inserção no mercado de trabalho não tem superado as conseqüências da divisão sexual do trabalho, que ainda trata as mulheres de forma discriminada seja no âmbito dos salários, das tarefas e até mesmo das possibilidades de ascensão social ${ }^{(10)}$. Vale destacar um crescente interesse por estudantes do sexo masculino pelo curso, já visível nos indicadores de ingressantes (16\%) e concluintes (13\%).

Constata-se que a (o) estudante ingressante, na sua maioria, já está inserida(o) no mundo do trabalho quando começa a estudar enfermagem, e isso pouco se modifica entre as (os) concluintes. Assim, essas(es) estudantes passam a conviver ao longo do curso com uma dupla jornada: trabalhar e estudar, pois ser estudante é ter um ofício, ou seja, ter uma ocupação. Ser aluna(o) é ter tarefas e horários a cumprir, é ser supervisionada(o), orientada(o) e avaliada(o) pelos mais experientes, é prestar contas de deveres e também direitos.

Se considerarmos o agravamento das condições de vida da população brasileira, seu empobrecimento, e dado que a democratização de acesso ao ensino superior se deu às custas do sistema privado de ensino, será possivel supor que para se manterem nos cursos, os estudantes necessitarão, de forma cada vez mais crescente, trabalhar para se sustentar no seu processo de formação. E esta parece ser uma tendência na profissão, qual seja, a de ter como sua clientela preferencial, estudantes que trabalham.

Outra tendência preocupante é a questão da base cultural do alunado. Destaca-se uma reduzida presença da educação superior no nivel de escolaridade de pais e mães das (os) estudantes de enfermagem, o que pode interferir na amplitude da formação cultural e humanística das (os) estudantes. Observa-se que $54 \%$ e $46 \%$ das (os) ingressantes e concluintes, respectivamente, têm sua trajetória escolar cursada exclusivamente no espaço da escola pública. Dadas às dificuldades que hoje caracterizam a escola pública, e contrastada com os indicadores socioeconômicos, deve-se considerar preocupante a base cultural das (os) estudantes de enfermagem. Fato que deve merecer atenção dos cursos e seus projetos pedagógicos, para tentar agregar valor a estudantes possivelmente debilitados culturalmente. Tarefa essa limitada na medida em que as circunstâncias de organização de tempo e vida das (os) estudantes sofrem influências da dupla jornada de trabalho.

O nível de conhecimento do idioma inglês é bastante sofrivel tanto na entrada como na saída do curso, ou seja, $54 \%$ e $48 \%$ praticamente nulo, respectivamente. Obviamente torna-se inevitável relacionar o dado com o nível socioeconômico da família que pertencem bem como ao nível de escolaridade de seus pais.

Fica evidenciado que $65 \%$ elegem a TV como seu meio de informação preferencial e, surpreendentemente, este índice cresce, nas (os) alunas (os) concluintes, para $68 \%$ quando, idealmente, se esperaria um amadurecimento que as (os) levasse a priorizar outros recursos de base mais crítica.

Qual é a diferença afinal entre um ofício qualquer e o ofício de estudante? Parece que a diferença está no fato de o ofício de estudante ter a sua razão de ser no favorecimento e/ou na consolidação da aprendizagem. É um ofício, por excelência, do aprender um saber e um saber - fazer, do aprender conteúdos e atitudes, conhecimentos e habilidades, matérias e hábitos de estudo. Mas como conviver e sobreviver diante de uma dupla jornada, ou seja, ser estudante e trabalhador?

É necessário considerar as (os) estudantes como sujeitos que tanto resistem e transgridem, como também se submetem e se adaptam às normas e rotinas da organização escolar. É necessário considerar que essas (es) estudantes constroem suas competências nesse contexto e movimento dialético.

Isto posto, como tendência, surge o desafio para os cursos de enfermagem, o de aceitarem o perfil de entrada, como dado de realidade sobre 0 qual não tem governabilidade e revisitarem suas formas de organização do trabalho pedagógico, tentando extrair alguma positividade da experiência de trabalho que as (os) estudantes trazem e do capital cultural que possuem.

A utilização da biblioteca, sinalizada como razoável pelas (os) estudantes, não supre o número ínfimo de horas que dedicam ao estudo que se mantém, tanto em ingressantes como concluintes, em torno de 1 a 2 horas semanais (40\% e $33 \%$ ). As defasagens decorrentes desses hábitos de estudo poderiam ser atenuadas pelo acesso aos recursos oferecidos pela tecnologia da informação. As (os) estudantes, no entanto, avaliam o uso do computador como ocasional, exceto no que se refere ao acesso a internet. Apesar do nível sócio-econômico em que se distribuem as (os) estudantes, concentrados em 1 a 3 salários mínimos, mais de $50 \%$ dos respondentes referem o uso de microcomputador em casa.

Observa-se um aumento da participação das (os) estudantes em atividades como pesquisa e extensão ao longo do curso. É preocupante, no entanto, o acentuado número de estudantes que referem nenhuma inserção nesse tipo de atividade. Várias leituras podem ser feitas: uma primeira em relação ao interesse da (o) própria (o) estudante; outra pela forma de organização dos tempos e espaços curriculares; uma outra diz respeito aos impedimentos oriundos da dupla jornada já destacada e por último a eventual escassez de investimento das IES na oferta dessas oportunidades de formação diferenciada, limitando alguns estudantes a uma formação reduzida à sala de aula.

As (os) estudantes ingressantes têm sido identificadas (os) com três tipos de imaturidade ${ }^{11}$ : cultural, ligada à falta de hábito de leitura; psicológica, ligada à não definição clara de objetivos e aspirações nem a certeza de que o curso escolhido atenderá às suas expectativas; lógica, ligada à falta de seqüência de raciocínio, quando manifesta por escrito o que pensa. Nesse sentido, espera-se que a trajetória no/do curso agregue esses e outros valores ao ofício da (0) estudante, o que com os indicadores aqui analisados não nos foi possível evidenciar, o que gera preocupação.

\section{PERSPECTIVAS E DESAFIOS}

A reflexão sobre a trajetória dos cursos de enfermagem no Brasil, 
triangulada com os dados do censo escolar e o material obtido pelo Enade, estimula os cursos a se perceberem nesse processo e a reverem suas decisões pedagógicas à luz do novo paradigma da formação do profissional de saúde, necessário para o país, devidamente informados sobre o perfil da clientela que busca na enfermagem sua realização/ certificação e a potência que seus processos de ensino devem ter para agregar-lhes valor em seu percurso formativo.

Os dados apresentados sobre a trajetória dos cursos de graduação em enfermagem, ainda que de maneira abreviada, evidenciam uma forte e desordenada expansão do número de cursos e de vagas por eles oferecidas, no período de 1991 a 2004 e, particularmente a partir de 1996, demonstrando assimetrias entre as diferentes regiões, como um desafio a ser enfrentado pela categoria.

Essa realidade permite refletir acerca dos desequilíbrios regionais, que parecem um problema a ser atacado de forma integrada e compartilhada entre o poder central, os estados, as IES e os serviços de saúde, bem como apontam para a necessidade da formulação de estratégias específicas visando a criação de parâmetros norteadores para a expansão do sistema, caso contrário, nos próximos anos, se observará a continuidade do crescimento da graduação com a permanência das assimetrias regionais com concentração nos grandes pólos econômicos.

Em qualquer que seja a região, é necessário consolidar a graduação para garantir sua qualidade e assegurar seu papel como instrumento de desenvolvimento científico, tecnológico, social, econômico e cultural. É fundamental, entretanto, a diminuição das desigualdades regionais, objetivando um desenvolvimento sustentável, o que pressupõe, necessariamente, menos desigualdades sociais.

Vale salientar, contudo, a necessidade de se buscar a qualidade na oferta desses cursos/vagas. É fundamental que se atente para o que se considera como parâmetros de qualidade nos cursos de enfermagem, de modo que a crescente e desordenada expansão quantitativa do número de cursos/vagas oferecidas no país, possa ser extensiva ao campo qualitativo, traduzido pela inserção de enfermeiros conscientes de sua função social e instrumentalizados para intervir propositivamente nos modelos de atenção à saúde.

A ampliação desordenada de vagas para os cursos de graduação em enfermagem sem o devido monitoramento das políticas de contratação dos profissionais, bem como a ausência de acompanhamento das ações exercidas tende a favorecer o desrespeito à lei do exercício profissional no que se refere às ações privativas da(0) enfermeira(o) que continuam, em algumas regiões, sendo executadas por profissionais de nível médio. Interfere também na sustentação do modelo de atenção à saúde, preconizado pelo SUS, que prevê a interiorização das ações de saúde. Ressalta-se, no entanto, que a expansão do número de vagas ainda é insuficiente para atender as múltiplas e diversas demandas de atenção à saúde da população nos niveis locais, regionais e nacionais.

A construção da qualidade resume-se em três compromissos: fazer bem o que se está fazendo mal, o que significa introduzir sistemas de diagnóstico do funcionamento dos diversos setores para identificar seus pontos fortes e fracos; fazer melhor o que se está fazendo bem, o que implica um plano estratégico de qualificação e desenvolvimento institucional capaz de ir consolidando e sustentando as realizações obtidas e fazer o que não se está fazendo e fazê-lo bem, isto é, incorporar dispositivos que facilitem e tornem possíveis inovações e processos de crescimento sistemáticos ${ }^{12}$

$\mathrm{Na}$ implementação da qualidade no processo de formação da(o) enfermeira(0), parece ser consensual a necessidade do realinhamento das(os) egressas(os) dos cursos, em conformidade com as Diretrizes Curriculares Nacionais do Curso de Graduação em Enfermagem.

Da análise dos dados relativos ao perfil do alunado dos cursos de graduação, reconhece-se que as (os) egressas (os) desses cursos necessitam de competências mais amplas para agir em prol da sustentação de um modelo de atenção à saúde com qualidade e assentado na integralidade, universalidade, intersetorialidade e controle social.

Os dados aqui apresentados reclamam por apropriação e interpretação pela comunidade acadêmica, podendo subsidiar reflexões dos sujeitos envolvidos no processo de formação das enfermeiras (os), bem como suas decisões internas na construção dos Projetos Pedagógicos (PP) dos cursos. Poderão, ainda, auxiliar na compreensão de que qualidade não é um conceito abstrato e depende também da existência de condições objetivas que determinam as relações entre professor/aluno/apropriação de competências e habilidades.

Ficou evidenciado que entre a entrada e a saída das (os) estudantes do sistema educacional há um processo que ocorre e é nesse espaço que a proposta institucional pode e deve fazer diferença. $E$ isto implica contrastar os dados de saída com o processo de construção de qualidade posto em movimento a partir de um claro diagnóstico das condições de entrada das (os) estudantes. Isso deve ser objeto de reflexão e pronto posicionamento do coletivo dos cursos frente aos dados que são oferecidos e que não podem permanecer latentes nos relatórios.

Da análise realizada, considera-se que:

- Uma boa formação em enfermagem não se reduz à competência técnica, meramente instrumental, mas deve ocupar-se em desenvolver e problematizar questões de amplo significado social. Isso é tarefa que deve nortear os PP dos cursos, independentemente de sua localização geográfica ou natureza jurídica. A concentração dos cursos na região sudeste, onde se concentram serviços de saúde mais especializados, não deve enviesar o eixo da formação.

- A presença marcante de alunas (os) que trabalham durante o curso deve ser explorada na positividade que contém, posto que podem enriquecer as reflexões, trazendo um olhar peculiar do processo de trabalho em que já estão inseridas (os). Paradoxalmente, estas (es) estudantes podem apresentar dificuldades concretas de acompanhamento do trabalho pedagógico, sobretudo se este estiver assentado numa pedagogia exclusivamente expositiva e enciclopédica. Sugere-se a incorporação de metodologias ativas que favoreçam 0 diálogo entre as diferentes culturas e visões que as (os) estudantes trazem. Igualmente práticas de avaliação colaborativas devem ser acionadas para firmação dos conceitos-chave da profissão e exercício do trabalho coletivo. A ética da solidariedade deve alicerçar as relações entre as (os) estudantes, antecipando as possibilidades de uma inserção no mundo de trabalho igualmente comprometida com a produção do bem comum. A avaliação da aprendizagem deve estar rigorosamente articulada ao processo de ensino-aprendizagem desenvolvido; séria 0 suficiente para impedir a banalização da certificação e ética o suficiente para evitar a exclusão sumária das (os) estudantes com déficits culturais sem que formas diferenciadas de mediação pedagógica tenham sido exaustivamente exploradas.

- A realidade do processo de trabalho da (0) enfermeira (0) é o foco para a discussão da formação e as bases do trabalho coletivo e da visão de integralidade da assistência devem ser respeitadas. 0 compromisso com os princípios norteadores do Sistema Único de Saúde precisa ser explorado em todas as atividades curriculares, considerandose esse Sistema, não como mero pano de fundo da formação, mas como eixo fundante da formação em saúde/enfermagem.

- A coerência com os objetivos proclamados nos PP deve ser buscada pelos cursos e isso implica a atenção com o não retorno ao processo de fragmentação curricular, motivado pela crença de que não se pode abdicar da quantidade de conteúdos e da exposição destes em sala de aula. 
Boas bibliotecas, com acervo adequado e atualizado não implicam bom ensino a menos que o acervo seja utilizado. Para tal, há necessidade de planejamento de horários livres para o trabalho autônomo do alunado e estratégias de ensino que incluam e explorem estes espaços. Deve haver cuidado nos horários de funcionamento das bibliotecas e laboratórios para diminuir as dificuldades das (os) estudantes que trabalham.

Trabalho coletivo é um componente vital para o bom exercício profissional, e que deve ser exercitado no processo de formação. Logo, implica ruptura com o conceito de que só se aprende em sala de aula e sob o comando do professor, em estimados 50 minutos de horas-aula. Sem desconsiderar a importância da mediação do docente, esta não deve prejudicar a experiência do trabalho grupal, devidamente orientado pelos objetivos da formação e estes objetivos devem nortear a composição de horários que favoreçam atividades integradoras e problematizadoras que não cabem na ditadura do relógio curricular.

O corpo docente deve estimular o olhar investigativo das (os) estudantes e evitar produzir apenas para as agências de fomento, tornando-se produtivos para a formação dos futuras (os) enfermeiras (os). Para isso, precisam de condições de trabalho e de que as políticas de Avaliação Institucional se confrontem com as políticas externas, especialmente as da Pos Graduação, notadamente centradas na produção intelectual das (os) docentes sem valorizar a convergência com a formação das (os) discentes.

- Os resultados das (os) estudantes no Enade devem servir de reflexão junto à comunidade da escola, não para festejar ou justificar conceitos, mas para permitir que o PP ganhe novamente primazia. A discussão sobre os resultados deve promover ação conseqüente da comunidade intra e extracurso e sempre que possível ação solidária entre os cursos da área. Trata-se de tentar estabelecer uma rede de sustentação a um projeto histórico para a formação de profissionais da saúde, ativadores de mudanças nos serviços de saúde, imprescindíveis à sustentação do SUS. Não podem servir, portanto, ao ranqueamento e nem devem levar à competição pura e simples por melhores notas para ostentar no mercado.

\section{REFERÊNCIAS}

1. Alcântara GA. Enfermagem como categoria profissional: obstáculos à sua expansão na sociedade brasileira (tese). São Paulo (SP): Escola de Enfermagem de Ribeirão Preto, USP; 1963.

2. Fernandes JD. Expansão do Ensino de Enfermagem no Brasil (tese). Salvador (BA) Escola de Enfermagem, Universidade Federal da Bahia; 1988.

3. Fernandes JD. $O$ ensino de enfermagem e de enfermagem psiquiátrica no Brasil (dissertação). Salvador (BA): Departamento de Medicina Preventiva da Faculdade de Medicina, UFBA; 1982.

4. Ministério da Saúde (Brasil). Fundação Serviços de Saúde Pública. Enfermagem: legislação e assuntos correlatos. $3^{\mathrm{a}}$ ed. Rio de janeiro (RJ): FSESP; 1974

5. Ministério da Educação (Brasil). Lei n9.394 de 20 de dezembro de 1996: estabelece as diretrizes e bases da educação nacional. Diário Oficial da União 1996 dez 23; (248): 833-41.

6. Ministério da Educação (Brasil). Conselho Nacional de Educação. Câmara de Educação Superior. Parecer CNE/CES nº 1133 de 7/8.
Brasilia (DF): ME; 2001.

7. Ministério da Educação (Brasil). Conselho Nacional de Educação. Câmara de Educação Superior. Resolução CNE/CES n ${ }^{\circ} 3$ de 7/11/ 2001: Diretrizes Curriculares Nacionais do Curso de Graduação em Enfermagem. Brasília (DF); ME; 2001.

8. Carvalho AC. Associação Brasileira de Enfermagem 1926-1976: documentário. Brasília (DF): ABEn; 1976.

9. Vieira ALS. Tendências do sistema educativo no Brasil: medicina, enfermagem e odontología. In: Ministério da Saúde. Observatório de Recursos Humanos em Saúde no Brasil: estudos e análises. Brasilia (DF): MS, 2004.

10. Paiva MS. Enfermagem brasileira: contribuição da ABEn. Brasília (DF): ABEn Nacional; 1999.

11. Teixeira E. As três metodologias. Petrópolis ( RJ): Vozes; 2005.

12. Zabalza MA. $O$ ensino universitário, seu cenário e seus protagonistas. Porto Alegre (RS): Artmed; 2004. 